\title{
Comprehensive Evaluation and Analysis of Teaching and Research Performance of Art Majors
}

\author{
https://doi.org/10.3991/ijet.v15.i20.17425 \\ Yin Lyu ${ }^{\square}$, Xue Yang \\ Huaiyin Normal University, Huaian, China \\ 8201711037@hytc.edu.cn \\ Jiang Yao \\ Shenzhen University, Shenzhen, China
}

\begin{abstract}
The growing popularity of art majors is overshadowed by the difficulty for art graduates to find a decent job. The teaching and research (T\&R) performance of art majors should be evaluated comprehensively, such as to optimize resource allocation and improve teaching quality. Based on performance evaluation theory and input-output theory, this paper summarizes the features, problems and problem causes of performance evaluation for art majors. From the dimensions of teaching and research, a comprehensive index system was designed for $T \& R$ performance evaluation of art majors. On this basis, a performance evaluation model was constructed for art majors through principal component analysis (PCA). Finally, single-factor evaluation and comprehensive evaluation were conducted by our model on the T\&R performance of the school of art design and school of industrial design in a university. The results show that: The performance evaluation of art majors is a small-scale yet complex and professional task, but the current evaluation methods lack sufficient attention, professionality, and targeted indices. The school of art design had a slightly higher ratio of excellent theses than the school of industrial design, reflecting the difference between the two schools in teaching results and quality. The school of industrial design invested much more than the school of art design. Both schools had improved the T\&R outputs and comprehensive performance score since 2011, and the school of industrial design made the greater improvement in the comprehensive performance score. The research sheds new light on comprehensive evaluation of $T \& R$ performance in art majors.
\end{abstract}

Keywords-Art majors, performance evaluation, evaluation index system, comprehensive evaluation of teaching and research $(T \& R)$ performance.

\section{Introduction}

Following the continuous improvement of their living standards, the people have started to pursue spiritual and cultural life rather than only the material life, and the aesthetic demands for products and living environment have also increased continu- 
ously. Facing this development trend, various universities have opened the art majors. With the year-by-year popularization of art major and expanded enrollment of colleges, the society's demands for art majors have also become saturated. Under this background, an increasing attention is paid to the quality and efficiency of art majors. The performance evaluation of art majors is an important means to improve the quality of running schools, cultivate high-quality talents, accelerate connotative development, and improve operating efficiency.

The research on performance evaluation of colleges originated from abroad. The United States was the first country to implement college performance evaluation as early as the 1950s [1]. College performance evaluation has become an important basis for government funding and management of college [2]. In recent years, many scholars in China have also put forward their own views on performance management. For example, some scholars believe that the college performance should comprehensively consider the contributions of colleges to talent leadership, service to society, talent training and scientific research, but not be limited to financial investment rate [3]; other scholars pointed out that China's performance evaluation system has problems such as closedness, mystery, blindness, and randomness, and it still stays at the primitive level [4]. The current evaluation index system of higher education is a relatively comprehensive system composed of 55 performance evaluation indicators proposed by American scholars [5]. The key performance indicators were used to set up a university performance evaluation system by some scholars [6]. Also, there are certain domestic scholars who have designed a college management performance evaluation system consisting of 27 indicators and divided it into two aspects: management performance and financial performance [7]. Looking through the references, it can be found that the current domestic and foreign research on the performance evaluation of colleges involves the construction of indicator systems, specific applicable research methods and related empirical cases [8], but there have been few studies on the performance evaluation of art colleges or art majors. Among the existing researches, some emphasized the establishment of a performance-based salary system and a job appointment system based on performance appraisal [9], or adopted the CIPP education evaluation model to evaluate the practical teaching of art academies [10]. There are also a few relevant theoretical and empirical studies on the teaching quality and performance evaluation of teachers in art colleges [11].

As above, this paper first analyzes the features, problems and problem causes of the performance evaluation of art majors based on performance evaluation theory and input-output theory. Then, combining the previous research results and the performance evaluation characteristics of art majors in the new era, it designs an index system for the T\&R performance evaluation of art majors. On this basis, a related mathematical model was constructed through the PCA. Finally, single-factor evaluation and comprehensive evaluation were conducted on the T\&R performance of the School of Art Design and School of Industrial Design in a university. 


\section{Related Theoretical Basis}

\subsection{Theoretical basis of performance evaluation}

The input-output theory in economics is the basic analysis theory of performance evaluation. The early input-output theory was measured by the amount of money invested and the amount of money earned. But now the fixed assets such as equipment and human capital are also included in the input, and the quality difference between outputs is also an important part of the output [12].

\subsection{Comprehensive performance evaluation}

Teaching, scientific research, and serving the society are the three basic functions of universities [13]. Combining the results of previous research and the survey results of art majors in universities [14], this paper divides the performance evaluation of art majors into four categories: teaching, scientific research, administration, and cultural communication. The comprehensive performance evaluation involves two aspects: art professional teaching and scientific research.

\section{Features and Problem Analysis of Performance Evaluation of art Majors in the New Era}

\subsection{Features of performance evaluation of art majors}

The teaching of art major is a complex system with multiple inputs and outputs. Therefore, the performance evaluation of art majors is complicated [15], reflecting in the diversification of educational components. Human input is the soul of art major input. The human here refers to the people with a certain level of knowledge, because the art teachers are both art creators and art talent trainers. For the material input, the evaluation of art majors is also more complicated when compared with other ordinary majors, e.g., the evaluation of a work of art should consider its reputation value, collection value, cost price, etc., so the fair value is used instead of book value [16]. Financial input is basically similar to that of other majors, including financial allocations, superior subsidies, etc. In addition, the performance evaluation of art majors follows the general economic law, and the input and output show a nonlinear law [17].

Besides, the performance evaluation of art majors is professional. The combination of education and practice is the basic principle in educational behavior [18]. Art majors have higher requirements for practical skills. Thus, artistic achievements must also be included in the performance evaluation system of art majors.

Furthermore, the performance evaluation of art majors is small-scale. At present, undergraduate education in China's universities has successfully turned to the stage of popular education. Since 1999, the number of graduate students has also increased on 
a large scale, and the number of doctoral students has shown a slow growth trend, while the number of students in art colleges grows slowly, showing a relatively stable trend. Figure 1 shows the number of students enrolled in art colleges in recent years [19]. This is mainly because art majors usually adopt small class teaching, and requires more teachers and teaching resources; also, it needs long-term training. The shortage of students limits the number of students in art colleges to a certain extent. Despite of the enrollment expansion, art major is far behind other disciplines in terms of the scale of running a school, and the maturity of running a school. Therefore, a unique performance evaluation system should be designed according to the actual situation of art majors.

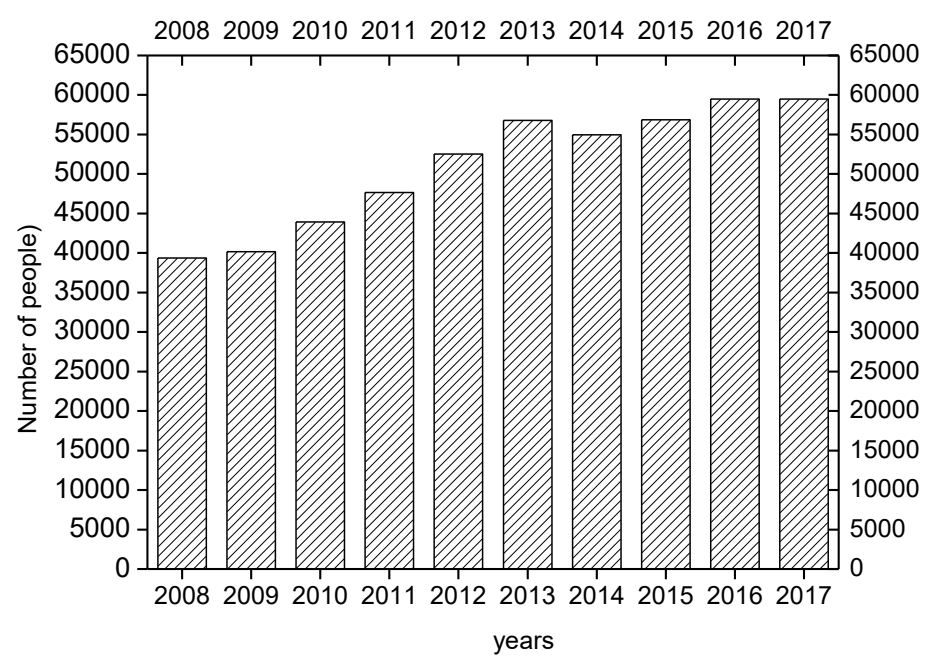

Fig. 1. Number of students enrolled in art colleges in recent years

\subsection{Analysis for performance evaluation problems of art majors}

At present, the performance evaluation for art majors is not perfect, nor does it consider the features of art majors. The specific problems are as follows:

Inadequate attention: The performance evaluation of art majors has not been valued by the college managers. The main reason is that most of them are scholars and experts in the field of art education, and in the management process, they can easily ignore the economic cost and make decision-making investment purely from the perspective of art, and lack a clear awareness of performance management.

Insufficient professionalism: At this stage, the performance evaluations of art majors are mostly made in the form of large-scale survey reports issued by superiors, which lack enough systematicness and execution force. Different from other majors, art majors emphasize resource input and elite output [20]. Therefore, a professional evaluation system should be designed according to the features of art majors. 
Lack of targeted evaluation indicators: At present, the performance evaluation indicators used by colleges emphasize scientific research and ignore teaching. However, due to the particularity of the art education model, its educational output is diversified, and the evaluation results should not be limited to the number of topics and theses, but focusing more on quantity and quality of artistic works. Therefore, the performance evaluation of art majors should be improved on the basis of previous evaluation indicators, to design the appropriate performance evaluation indicators for art majors.

\section{Comprehensive Evaluation and Analysis of T\&R Performance of Art Majors}

\subsection{Design of evaluation indicators}

Evaluation indicators are the basic elements and key links of performance evaluation, which directly determine its effectiveness. Comprehensive evaluation of T\&R performance of art majors is to judge whether the educational resources of art majors are maximized. In this paper, the input-output performance model was used to comprehensively evaluate the $T \& R$ performance of art majors. The performance indicators were designed from the two dimensions of teaching and research. It follows the principles of vagueness, combination of comprehensiveness and representativeness, operability and comparability, and dynamic development. Figure 2 shows the comprehensive evaluation index system for T\&R performance of art majors. For better understanding, evaluation indicators were explained as follows:

Teaching input: Teaching input was studied from three aspects of human, financial and material resources [21], including the following indicators:

Total staffs: The total number of full-time and part-time staffs currently undertaking tasks in teaching and scientific research; the number of part-time staffs are calculated according to the proportion of their workload.

Full-time teaching staff: the total number of full-time teachers in art majors.

Teaching business expenses: as the main source of expenditures for teaching and scientific research of art majors, it includes teaching expenses, research expenses, and social security expenses etc. [22].

The purchase fee of teaching equipment such as art works, sculpture works, and multimedia equipment for art majors.

Research input: Scientific business expenses: it refers to the scientific research expenditure in the teaching expenses mentioned above.

Books, digitization, and laboratory construction fees: expenditures for the construction of key art laboratories, network digitization construction costs, and book purchase fees.

Doctoral degree ratio of full-time teachers: the proportion of full-time teachers with doctoral degrees to the total number of teachers. 


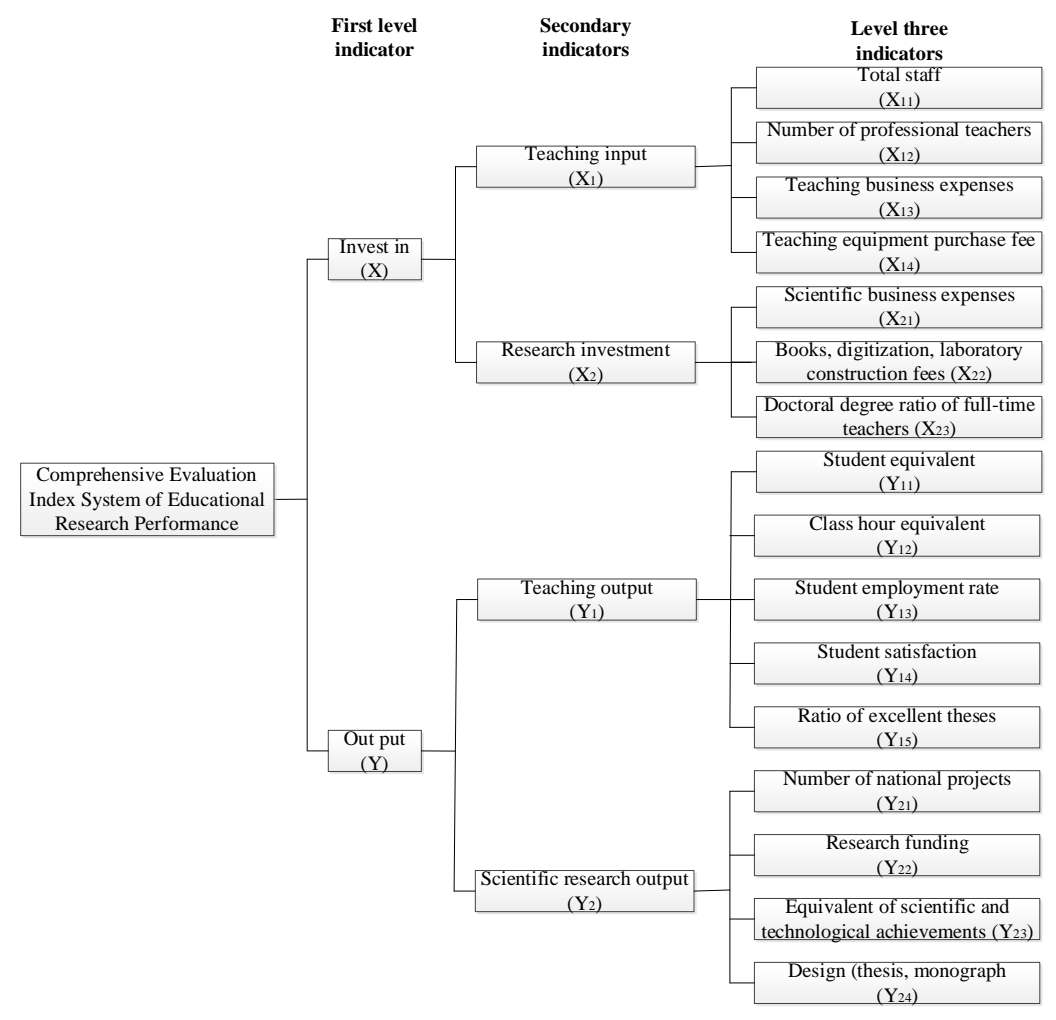

Fig. 2. Comprehensive Evaluation Index System of T\&R Performance

Teaching output: Student equivalent [23]: Student Equivalent $=$ Undergraduate $+1.5^{*} \mathrm{MBA}+1.5 *$ Engineering Master+2*Academic

Master $+3 *$ Doctorate $+4 *$ Postdoctoral

Class hour equivalent: The number of equivalent class hours undertaken by all teachers in art majors for teaching and scientific research.

Ratio of excellent theses [24]: the ratio of the sum of the bachelor's, master's, and doctoral provincial graduation design (thesis) according to the proportions of 1:2:3 to the number of student equivalent.

Research output: Number of national projects that art teachers have applied for.

Research funding: to a certain extent, it can reflect the research capabilities of art majors, specifically referring to the total amount of project funding at all levels that art majors have applied for.

Equivalent of scientific and technological achievements: it refers to the sum of scientific and technological progress, invention and creation, natural science and other awards received from various design works and scientific research results, which can reflect the quality of research output.

Design (thesis, monograph): Design (thesis, monograph) $=25 *$ national level+12*national level+5*local level+20*monograph [25]. 


\subsection{Data analysis methods}

Data standard processing and correlation analysis: In this paper, PCA was adopted to analyze and model the data, the dimensionality of the comprehensive evaluation indicators was reduced for the $T \& R$ performance of art majors, to finally obtain the comprehensive variables that can reflect the original indicators. In order to eliminate the dimension of the original data and make the collected data comparable, this paper uses the $\mathrm{Z}$ standardization method to normalize the data [26], as shown in Equation (1).

$$
Z X_{i}=\left(X_{i}-u_{i}\right) / \sigma_{i}
$$

where, $\mathrm{ZXi}$ is the data obtained after standardization, that is, the converted input and output are ZX11- ZX23 and ZX11- ZX24 respectively; Xi is the collected sample data, and the standard deviation and average of the sample data $\mathrm{Xi}$ are $\sigma \mathrm{i}$ and ui respectively.

The typical correlation analysis was performed to screen out the correlation between input and output indicators, and further eliminate the irrelevant indicators in the two sets of variables. Standardize the original index data matrix to obtain the correlation matrix, as shown in equation (2),

$$
R=\left[\begin{array}{ll}
R_{11} & R_{12} \\
R_{21} & R_{22}
\end{array}\right]
$$

where, R21=R12, R11, R12 and R21 respectively represent the matrix of correlation coefficients between X11 and X23, Y11 and Y24, Xni and Yni.

The eigenvalues of the matrix $A=R 11-1 R 12 R 22-1 R 21$ and $B=R 22-1 R 21 R 11-1 R 12$ were calculated to determine the significance of the correlation. The typical correlation between the two groups of variables was analyzed using the SPSS.

Determination of comprehensive variables and performance scores: The PCA method was also used to extract comprehensive variables from the remaining input and output variables. The number of comprehensive variables was finally determined according to the scree plot and the total variance explained, and then the total scores of input and output were calculated separately, as shown in Equation (3). The comprehensive performance score is calculated in equation (4).

$$
Z \quad \text { Input (output) }=F_{1} \times a_{1}+F_{2} \times a_{2}+\cdots+F_{q} \times a_{q}
$$

$$
\text { Comprehensive performance score }=\frac{Z \quad \text { Input }}{Z \quad \text { output }} \times 100 \%
$$

where, the variance explained by the comprehensive variable F1, F2, .., Fq is represented by a1, a2, .., aq respectively. 


\subsection{Empirical analysis for comprehensive evaluation of $T \& R$ performance of art majors}

Data collection and analysis: Considering the huge amount of information required for the comprehensive evaluation of T\&R performance, and the availability of comprehensive data, this paper collects and selects complete T\&R data of the School of Art Design and the School of Industrial Design in one university. Comprehensive evaluation and analysis were conducted on the T\&P performance of the two schools. Table 1 lists the 2017 and 2018 data of various indicators collected from the two schools.

Table 1. Data on various indicators of the School of Art Design and Industrial Design in 2017 and 2018

\begin{tabular}{|l|c|c|c|c|}
\hline \multicolumn{1}{|c|}{ Index } & \multicolumn{2}{c|}{$\begin{array}{c}\text { School of Art Design } \\
\mathbf{2 0 1 7} \mathbf{2 0 1 8}\end{array}$} & \multicolumn{2}{c|}{$\begin{array}{c}\text { School of Industrial Design } \\
\mathbf{2 0 1 7} \mathbf{2 0 1 8}\end{array}$} \\
\hline X11 & 76 & 81 & 168 & 252 \\
\hline X12 & 86 & 99 & 220 & 228 \\
\hline X13 (Ten thousand yuan) & 86.75 & 118.27 & 214.64 & 228.4 \\
\hline X14 (Ten thousand yuan) & 6.54 & -8.7 & 35.9 & 39.9 \\
\hline X21 (Ten thousand yuan) & 602 & 701 & 1650 & 1915 \\
\hline X22 (Ten thousand yuan) & 361.8 & 393.02 & 3334.56 & 3567.43 \\
\hline X23 (\%) & 65 & 83 & 73 & 89 \\
\hline Y11 & 1459.6 & 1438.3 & 4258 & 4319.7 \\
\hline Y12 (class) & 17577 & 17768 & 49656.2 & 52043 \\
\hline Y13 (\%) & 81.33 & 80.69 & 96.92 & 94.39 \\
\hline Y14 (\%) & 87.33 & 88.39 & 88.22 & 88.89 \\
\hline Y15 (Articles/100 people) & 0.59 & 0.88 & 0.43 & 0.46 \\
\hline Y21 & 0 & 1 & 4 & 12 \\
\hline Y22 & 345.5 & 78.43 & 353.55 & 968.43 \\
\hline Y23 & 2 & 1 & 1 & 2 \\
\hline Y24 & 1153 & 1049 & 2104 & 2581 \\
\hline
\end{tabular}

Import the collected data into SPSS, standardize the input and output indicators, and use the standardized data for correlation analysis. The correlation analysis between the input indicators showed that the indicator X11 was significantly related to the X22; there was significant correlation between the other indicators. From the results of the correlation analysis between the output indicators, it can be seen that that there was a significant correlation between the four indicators: Y11, Y12, Y13, and $\mathrm{Y} 24$, indicating that both the input and output indicators can use the PAC method to extract comprehensive variables.

Figure 3 shows the scree plot of the comprehensive variables extracted from the output indicators. Three comprehensive variables were extracted to reflect the information of the original indicators. Through rotating component matrix and the components, the extracted indicators from the principal components 1, 2, 3 were Y11, Y12, Y13, Y15, and Y24, Y22 and Y23, respectively. According to the percentage of variance explained by each comprehensive variable $\mathrm{Fi}$, a regression equation of output was constructed, as shown in equation (5): 
Total output $\quad Z_{o}=52.76 \times F_{21}+26.64 \times F_{23}+20.6 \times F_{23}$

Similarly, the income regression equation is obtained:

Total output $\quad Z_{I}=56.38 \times F_{11}+43.62 \times F_{12}$

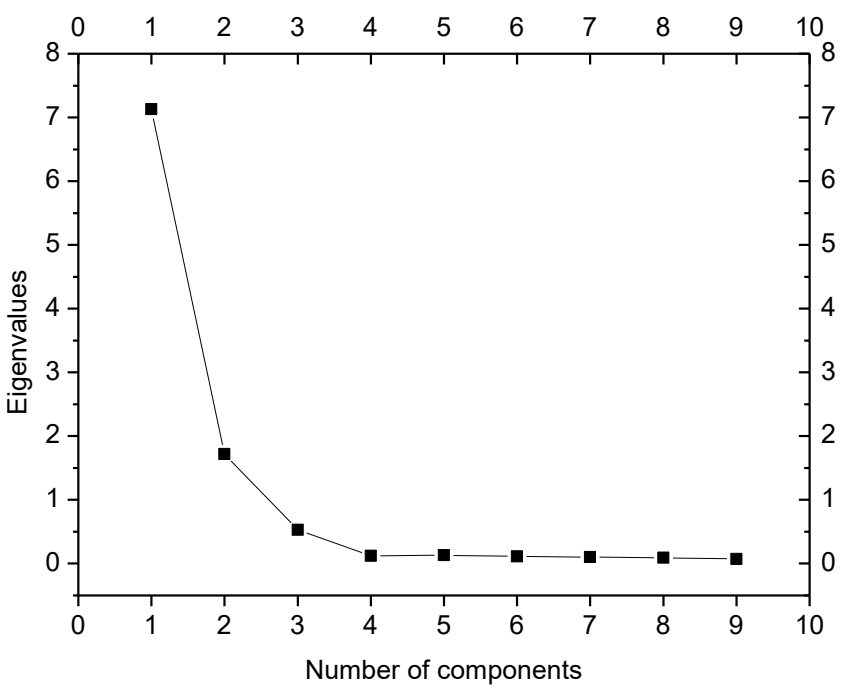

Fig. 3. Scree plot

Single factor analysis of $\mathbf{T} \& \mathbf{R}$ performance: The analysis for the collected data found that the teaching level of art majors can be reflected by three indicators: the ratio of excellent theses, teaching business fees and the average class hours of teachers. Table 2 lists the teaching scores of the two selected schools. It can be seen from the table that the ratio of excellent theses of the School of Art and Design was slightly higher than that of the School of Industrial Design, reflecting the difference in the teaching results and quality between the two schools. As a science and engineering department, the School of Industrial Design had a larger number of students, the average teaching expense per student was significantly lower, and its class hours were also slightly higher when compared with the school of art design.

Table 2. Comparison of teaching level between School of Art Design and School of Industrial Design

\begin{tabular}{|l|c|c|c|c|}
\hline \multicolumn{1}{|c|}{ Art major } & Years & $\begin{array}{c}\text { Z1 Teaching expenses } \\
\text { per student }\end{array}$ & Z2 class & $\begin{array}{c}\text { Y15 Award rate of } \\
\text { graduation thesis }\end{array}$ \\
\hline \multirow{2}{*}{ School of Art Design } & 2011 & 595.15 & 202.13 & 0.6 \\
\cline { 2 - 5 } & 2012 & 817.43 & 181.32 & 0.9 \\
\hline School of Industrial Design & 2011 & 507.31 & 226.21 & 0.42 \\
\hline & 2012 & 464.52 & 229.69 & 0.39 \\
\hline
\end{tabular}


From the collected data, it's also found that the scientific research level of art majors can be reflected by the four indicators: publish designs (papers and monographs) per teacher, scientific research funding per teacher, scientific business expenses per student, and equipment amount per student. Table 3 lists the scores of the scientific research level of the two schools. From the table, it can be seen from the table that research input of the School of Art Design's was significantly lower; from the perspective of research output, the School of Industrial Design in 2011 was lower than that of the School of Art, while its output was significantly improved in 2012.

Table 3. The research level of the School of Art and Industrial Design

\begin{tabular}{|l|c|c|c|c|c|}
\hline \multicolumn{1}{|c|}{ Art major } & Years & $\begin{array}{c}\text { Amount of equip- } \\
\text { ment per student } \\
\text { (Yuan) }\end{array}$ & $\begin{array}{c}\text { scientific business } \\
\text { expenses per } \\
\text { student (Yuan) }\end{array}$ & $\begin{array}{c}\text { Research } \\
\text { funding per } \\
\text { teacher (Yu- } \\
\text { an) }\end{array}$ & $\begin{array}{c}\text { All teachers publish } \\
\text { designs (papers, mono- } \\
\text { graphs) (Yuan) }\end{array}$ \\
\hline $\begin{array}{l}\text { School of Art } \\
\text { Design }\end{array}$ & 2011 & 2472.55 & 44.11 & 40667.75 & 13.17 \\
\cline { 2 - 6 } & 2012 & 2727.03 & 59.98 & 7770.43 & 10.72 \\
\hline $\begin{array}{l}\text { School of } \\
\text { Industrial } \\
\text { Design }\end{array}$ & 2011 & 7831.52 & 81.87 & 15980.45 & 9.64 \\
\hline & 2012 & 8266.63 & 90.02 & 42346.86 & 11.35 \\
\hline
\end{tabular}

Comprehensive evaluation and analysis of T\&R performance: Table 4 and Figure 4 show the total input, total output, and comprehensive performance scores of the two schools calculated as above. From them, it can be seen that compared with 2011, the total input in T\&R decreased in the School of Art Design, and that of the School of Industrial Design increased in 2012; the T\&R output and the comprehensive performance evaluation of the two schools were improved, and the comprehensive evaluation scores of the T\&R performance in the School of Industrial Design has improved more significantly.

Table 4. The total input, total output and comprehensive performance scores of the School of Art and School of Industrial Design

\begin{tabular}{|l|c|c|c|c|}
\hline \multicolumn{1}{|c|}{ Art major } & Years & Total investment & Total output & Performance \\
\hline \multirow{2}{*}{ School of Art Design } & 2011 & -67.92 & -39.7 & 58.46 \\
\cline { 2 - 5 } & 2012 & -54.91 & -63.41 & 115.53 \\
\hline School of Industrial Design & 2011 & 58.3 & 29.72 & 51.1 \\
\hline \multicolumn{2}{|c|}{2012} & 64.52 & 73.43 & 113.69 \\
\hline
\end{tabular}




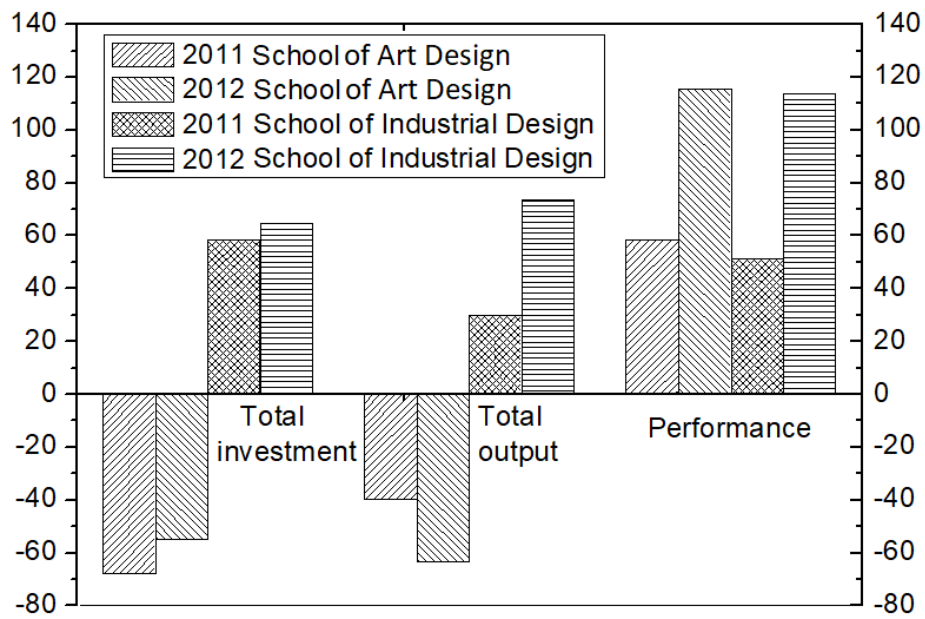

Fig. 4. The total input, total output and comprehensive performance scores of the School of Art Design and School of Industrial Design

\section{Conclusion}

Compared with other majors, the $\mathrm{T} \& \mathrm{R}$ of art majors is unique. Its performance evaluation involves multiple input-output elements. Based on performance evaluation theory and input-output theory, this paper studies the comprehensive evaluation of $T \& R$ performance of art majors in the new era through empirical analysis. The specific conclusions are as follows:

1. The performance evaluation of art majors is small-scale, but complex and professional. It still has the problems such as inadequate attention, insufficient professionality, and lack of targeted indicators.

2. According to the input-output theory, a comprehensive evaluation index system for the T\&R performance of art majors was designed from the two dimensions of teaching and research. On this basis, a mathematical model was constructed accordingly through the PCA. Besides, taking a university's School of Art Design and Design and School of Industrial Design as examples, single-factor evaluation and comprehensive evaluation analysis were conducted on their $\mathrm{T} \& \mathrm{R}$ performance.

3. The single-factor analysis results of teaching performance showed that the ratio of excellent theses in the School of Art and Design was slightly higher than that of the School of Industrial Design, reflecting the difference in the teaching results and quality between the two schools. The single-factor analysis results of scientific research performance showed that the School of Industrial Design invested more than the School of Art Design; in 2011, the T\&R output of the School of Industrial Design was lower than that of the School of Art Design, while in 2012, it was improved greatly, apparently higher than the School of Art Design. 
4. The comprehensive evaluation results of $T \& R$ performance showed that compared with 2011, the total input in T\&R has decreased in the School of Art Design, and that in the School of Industrial Design has increased in 2012; both schools had improved the T\&R outputs and comprehensive performance score, and the School of Industrial Design made the greater improvement in the comprehensive performance score.

\section{References}

[1] Chen, J.F., Hsieh, H.N., Do, Q.H. (2015). Evaluating teaching performance based on fuzzy AHP and comprehensive evaluation approach. Applied Soft Computing, 28: 100-108. https ://doi.org/10.1016/j.asoc.2014.11.050

[2] Vernon, M.M., Balas, E.A., Momani, S. (2018). Are university rankings useful to improve research? A systematic review. PloS one, 13(3): e0193762. https://doi.org/10.1371/journal. pone. 0193762

[3] Post, T. (2001). Performance evaluation in stochastic environments using mean-variance data envelopment analysis. Operations Research, 49(2): 281-292. https://doi.org/10.1287/ opre.49.2.281.13529

[4] Kao, C., Pao, H.L. (2009). An evaluation of research performance in management of 168 Taiwan universities. Scientometrics, 78(2): 261-277. https://doi.org/10.1007/s11192-007$\underline{1906-6}$

[5] Veglis, A.A., Barbargires, C.A., Pombortsis, A.S. (2002). Teaching performance evaluation of multiprocessor architectures with Mathcad and MathConnex. IEEE Transactions on Education, 45(3): 231-237. https://doi.org/10.1109/te.2002.1024615

[6] Zhou, L., Li, H., Sun, K. (2017). Teaching performance evaluation by means of a hierarchical multifactorial evaluation model based on type-2 fuzzy sets. Applied Intelligence, 46(1): 34-44. https://doi.org/10.1007/s10489-016-0816-9

[7] Veglis, A.A., Barbargires, C.A., Pombortsis, A.S. (2002). Teaching performance evaluation of multiprocessor architectures with Mathcad and MathConnex. IEEE Transactions on Education, 45(3): 231-237. https://doi.org/10.1109/te.2002.1024615

[8] Peek, P.M. (2012). Environment and object: recent african art. frances young tang teaching museum and art gallery, skidmore college, saratoga springs, new york, february 5-july 31, 2011. African Arts, 45(1): 83-85. https://doi.org/10.1162/afar.2012.45.1.83

[9] Stone, L., Garrison, J., Tanner, L.N. (1997). Dewey and eros: wisdom and desire in the art of teaching. Journal of Aesthetic Education, 33(1): 116. https://doi.org/10.2307/3333747

[10] Hall, J. (2010). Making art, teaching art, learning art: Exploring the concept of the artist teacher. International Journal of Art \& Design Education, 29(2): 103-110. https://doi.org/ 10.1111/j.1476-8070.2010.01636.x

[11] Calingaert, P. (1967). System performance evaluation: survey and appraisal. Communications of the ACM, 10(1): 12-18. https://doi.org/10.1145/363018.363040

[12] Grave, P., Maccheroni, M., McCarthy, B., Chase, E.S., Cort, L.A., Douglas, J.G., Jett, P. (2009). Scientific research on historic asian ceramics: proceedings of the fourth forbes symposium at the freer gallery of art. Bioinformatics, 15(3): 211-218. https://doi.org/10.54 79/sil.930786.39088016522088

[13] Yusof, M. R., Yaakob, M. F. M., Ibrahim, M. Y. (2019). Measurement model of teaching competency of secondary school teachers in Malaysia, International Journal of Emerging Technologies in Learning, 14(20), 157-164. https://doi.org/10.3991/ijet.v14i20.11465 
[14] Wahed, W. J. E., bin Husain, A. H., Wahed, W. J. E., Pitil, P. P. (2019). The influence of Artist in Schools (AiS) program and the ARCS motivational model on students' creativity and motivation in visual art, International Journal of Emerging Technologies in Learning, 14(20), 149-156. https://doi.org/10.3991/ijet.v14i20.11464

[15] Rangnekar, V.M. (2002). Art of excellence in scientific research. Cancer Biology \& Therapy, 1(1): 72-73. https://doi.org/10.4161/cbt.1.1.47

[16] None. (1952). Scientific research and the art gallery: nuffield foundation research scholarships at the national gallery. Nature, 169(4294): 264-265. https://doi.org/10.1038/ $\underline{169264 \mathrm{a} 0}$

[17] Scott, D.A. (2008). Scientific research in the field of asian art: proceedings of the first forbes symposium at the freer gallery of art. Studies in Conservation, 53(1): 76-78. https:// doi.org/10.1179/sic.2008.53.1.76

[18] None. (1934). Scientific research on works of art. Nature, 134(3379): 172-173. https://doi. org/10.1038/134172d0

[19] Zhang, X., Shi, W. (2019). Research about the university teaching performance evaluation under the data envelopment method. Cognitive Systems Research, 56: 108-115. https://doi. org/10.1016/j.cogsys.2018.11.004

[20] Albert, A., Granadino, B., Plaza, L. (2007). Scientific and technological performance evaluation of the Spanish Council for Scientific Research (CSIC) in the field of Biotechnology. Scientometrics, 70(1): 41-51. https://doi.org/10.1007/s11192-007-0103-y

[21] Győrffy, B., Nagy, A.M., Herman, P., Török, Á. (2018). Factors influencing the scientific performance of Momentum grant holders: an evaluation of the first 117 research groups. Scientometrics, 117(1): 409-426. https://doi.org/10.1007/s11192-018-2852-1

[22] Pan, W.T., Huang, C.E., Chiu, C.L. (2016). Study on the performance evaluation of online teaching using the quantile regression analysis and artificial neural network. The Journal of Supercomputing, 72(3): 789-803. https://doi.org/10.1007/s11227-015-1599-1

[23] Lin, R., Chen, Z. (2008). New DEA performance evaluation indices and their applications in the American fund market. Asia-Pacific Journal of Operational Research, 25(04): 421450. https://doi.org/10.1142/s0217595908001882

[24] Frixione, E., Ruiz-Zamarripa, L., Hernández, G. (2016). Assessing individual intellectual output in scientific research: Mexico's national system for evaluating scholars performance in the humanities and the behavioral sciences. PloS one, 11(5): e0155732. https://doi.org/1 0.1371/journal.pone.0155732

[25] Basu, A., Banshal, S.K., Singhal, K., Singh, V.K. (2016). Designing a Composite Index for research performance evaluation at the national or regional level: ranking Central Universities in India. Scientometrics, 107(3): 1171-1193. https://doi.org/10.1007/s11192$\underline{016-2009-\mathrm{Z}}$

[26] Li, F., Yi, Y., Guo, X., Qi, W. (2012). Performance evaluation of research universities in Mainland China, Hong Kong and Taiwan: based on a two-dimensional approach. Scientometrics, 90(2): 531-542. https://doi.org/10.1007/s11192-011-0544-1

\section{$7 \quad$ Authors}

Yin Lyu Associate professor, College of music, Huaiyin Normal University. master's degree, Graduated from Belarusian State University of Culture and Arts. studying in the doctoral dance class of Taipei University of art, Taiwan, China. Member of Jiangsu Dancers Association, director of Huai'an Dancers Association, Liaoning Provincial Youth Social Science Talent Expert Database, member of the 
expert group of the Academy of Master of Arts in Dance. Research direction: Digital dance, dance teaching reform, etc (email: 8201711037@ @ytc.edu.cn).

Xue Yang Lecturer, College of music, Huaiyin Normal University. master's degree, Sehan University, South Korea. Member of Jiangsu Dancers Association, Member of Huai'an Dancers Association. Research direction: dance theory, dance teaching reform, etc (email: $8201711038 @$ hytc.edu.cn).

Jinag Yao Assistant professor at Shenzhen University. Doctor, graduated from Kyung Hee University, South Korea. Member of Shenzhen Dancers Association, Deputy Secretary General of Shenzhen Nanshan Dancers Association. Research direction: dance choreographer teaching and practice, dance teaching reform, etc (email: yjaznj@hotmail.com).

Article submitted 2020-07-31. Resubmitted 2020-09-04. Final acceptance 2020-09-05. Final version published as submitted by the authors. 